\title{
Experimental verification of shrinkage due to drying in concrete under varying humidity conditions in accordance with the Eurocode2 standard
}

\author{
Wioletta Raczkiewicz ${ }^{1, *}$, Magdalena Bacharz ${ }^{1}$ \\ ${ }^{1}$ EDP Kielce University of Technology, Al. Tysiąclecia P.P. 7, Kielce, Poland
}

\begin{abstract}
The concrete shrinkage depends on many factors. There are the concrete mixture, dimensions of the element and environment conditions, mainly humidity. All these factors can be imposed under laboratory conditions and controlled. In field conditions, however, a constant humidity is not possible to keep. The paper presents the impact of relative humidity changes on the values of shrinkage strains. The experimental results obtained on the specimens (with size 150x150x600 mm) were compared with the values calculated in accordance with the Eurocode 2 standard. The specimens were made with basalt aggregate without admixtures or additives. Two kinds of cement were used in preparing the specimens: Portland and blast-furnace slag cement. All specimens were treated in water for 10 days in the first days after demoulding and then subjected to testing. During the 56 days the temperature was $22 \pm 2^{\circ} \mathrm{C}$, while the humidity decreased proportionally from $91 \%$ to $47 \%$. Strains were measured and the specimens were weighed to determine the mass loss. The experimental results were compared to the computational results. It should be concluded that they were not coherent in the case of ambient humidity exceeding $80 \%$ although it was accordance with the Eurocode 2 standard.
\end{abstract}

\section{Introduction}

Concrete shrinkage is described as a rheological phenomenon based on the occurrence of specific strains resulting from the physical and chemical processes, that occur both on the stage of concrete mixture binding (autogenous shrinkage), and later in the period of concrete hardening and drying (physical shrinkage) [1-3], which is schematically presented in Fig. 1.

The factors conditioning development of shrinkage are environmental conditions (particularly humidity), components in the concrete mixture (type and amount of cement, w/c factor, aggregate type and granular composition, as well as additives and admixtures used), as well as dimensions of the element and limitations of free strains in concrete (i.e. the reinforcement) $[1,2,4-6]$. Whereas, the influence of particular factors on the shrinkage size is variable, depending on a particular case of autogenous shrinkage and the shrinkage resulting from drying. Strains caused by autogenous shrinkage are generally related with

*Corresponding author: wiolar@tu.kielce.pl 




Fig. 1. Concrete shrinkage growth in time [3].

chemical hydration processes in cement and develop during the first days of concrete mixture binding $[1,2]$. They grow very rapidly, but they are not so large in relation to total strain measured in the later period. The autogenous shrinkage is an irreversible phenomenon and cannot be stopped, but when a proper cement or proper additives are used, it can be slowed down or slightly limited [4-7]. The physical shrinkage caused by drying has a significantly larger share in total shrinkage strains $[1,2,4,6,7]$. Strains resulting from a decreasing amount of water in the concrete microstructure grow in the long-term (even after years), but the largest increase is observed in first two-three months from pouring the concrete. Environmental conditions have a very large influence on its value, particularly ambient humidity $[1,2,4,8]$. When maintaining the respectively high level of humidity (i.e. intensive concrete curing) such type of shrinkage can be visibly slowed down, inhibited, and a reverse phenomenon, namely the swelling, can be even caused in the early stage of concrete binding and hardening, which happens for the concretes in the environmental humidity exceeding $95 \%[1,2]$. The second important factor influencing the size of concrete shrinkage is the type of the cement used [5-7,9]. According to [5], the shrinkage of normative cement mortars with CEM I, CEM II and CEM III cements is visibly diversified (Fig. 2). Depending on the cement used, the concrete structure is slightly different, as well as the size and shape of pores, which directly has an influence on the intensity of evaporation.

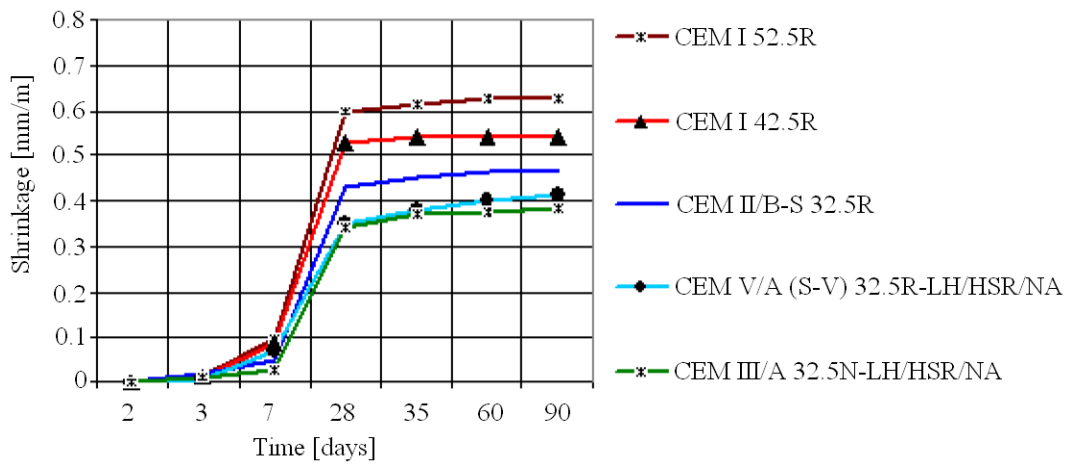

Fig. 2. Shrinkage of normative cement mortars [5].

In the construction industry with application of concrete, CEM I Portland cement is commonly used. Whereas, in order to limit the shrinkage strains, application of the CEM III cement with addition of a blast furnace slag or a fly ash is more profitable for the concrete [1,7]. The concretes with this type of cement are characterised by a lower hydration temperature, longer binding period and higher amount of gel pores versus capillary pores, when compared with the Portland cement concretes, and all such factors influence the limitation of shrinkage.

Guidelines for the evaluation of the shrinkage strain values in time were presented in the following standards PN-EN 1992-1-1 [10] and PN-EN 1992-2 [11], whereas in the [10] 
standard the general guidelines are provided for constructions made from concrete; in the [11] standard they are detailed for bridge constructions in terms of high-strength concrete, i.e. C55/67 grade and higher. The procedures presented in the standards include both the influence of internal (i.e. concrete mixture) and external (humidity) factors on the shrinkage size [8-11]. However, application of formulas for humidity not exceeding $\mathrm{RH}=80 \%$ is limited in the standard.

The research results concerning the shrinkage in concrete samples are presented in this paper, made with application of two cement types: CEM I Portland cement and CEM III blast furnace cement. The obtained results are analysed in the context of humidity changes, as well as in relation to the EN2 standard.

\section{Experimental research}

6 concrete samples with dimensions of $150 \times 150 \times 600 \mathrm{~mm}$ were prepared for the research. The samples were made with basalt aggregate from the Górażdże mine, without any admixtures and additives. They differed with cement type, having the preserved fixed weight proportion for components (Tab.1). Three elements with S1 symbol were made with CEM I 42,5N MSR/NA Portland cement from the Warta cement plant, and 3 other samples were marked as S2 and made from the CEM III/A 42,5N LH-HSR/NA blast furnace cement from the Małogoszcz cement plant (Tab. 1).

Table 1. Composition of concrete $\operatorname{mix}\left[\mathrm{kg} / \mathrm{m}^{3}\right]$.

\begin{tabular}{|c|c|c|c|c|c|c|}
\hline Symbol & $\begin{array}{c}\text { Basalt } \\
\mathbf{2 - 8}\end{array}$ & $\begin{array}{c}\text { Basalt } \\
\mathbf{8 - 1 6}\end{array}$ & $\begin{array}{c}\text { Sand } \\
\mathbf{0 - 2}\end{array}$ & $\begin{array}{c}\text { CEM I 42.5 N } \\
\text { MSR/NA }\end{array}$ & $\begin{array}{c}\text { CEM III/A 42.5N } \\
\text { LH-HSR/NA }\end{array}$ & Water \\
\hline S1 & 581 & 731 & 691 & 360 & $x$ & 180 \\
\hline S2 & 581 & 731 & 691 & $\mathrm{x}$ & 360 & 180 \\
\hline
\end{tabular}

The research procedure was made according to the ITB 194/98 Manual [13]. The samples were maintained in water for 10 days during the first days of forming, in order to eliminate the autogenous shrinkage, and then they were researched. After taking the samples from water, on each side wall two metal tags were glued for the longitudinal strain measurements (Fig.3).

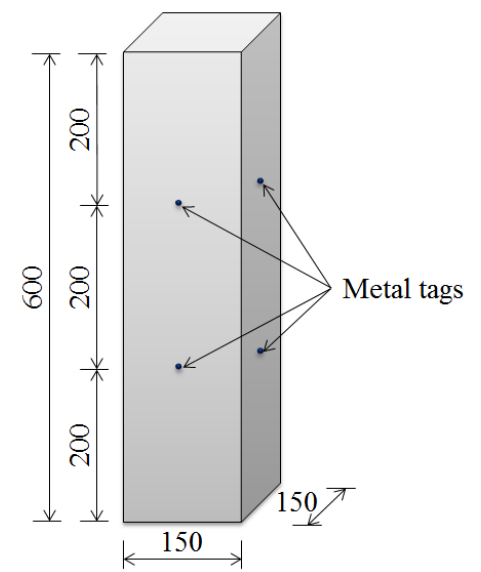

Fig. 3. Spacing for metal tags for the measurement of strains in the sample under test.

Such measurements were made with means of mechanical method, with application of the Demec extensometer (Fig. 4) having the $200 \mathrm{~mm}$ measurement base and accuracy of 
$0.002 \mathrm{~mm}$ (tensiometer constant $0.79 \times 10^{-5}$ ). After the executed measurements for basic strains at four walls in every sample and after weighting the samples, all samples were placed in the thermal chamber, where a constant temperature of $22 \pm 2^{\circ} \mathrm{C}$ was set. The research was made in the stipulated intervals, with consideration to the guidelines provided in the Instruction [13], at days: 1-8, 12, 16, 24, 28, 36, 47 and 56. Whenever the measurements were made, strains were measured and the samples were weighed, in order to determine the water mass loss, also humidity in the chamber was measured (that was not imposed and gradually decreased in time, from $91 \%$ to $47 \%$ ). The obtained experimental results were compared with strains values calculated according to the standard [10].

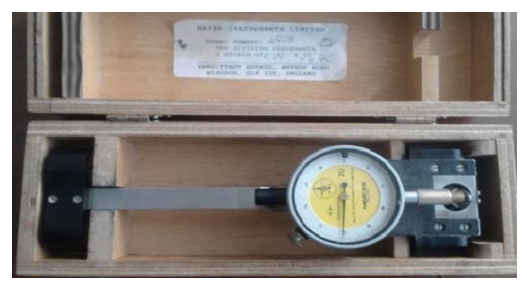

Fig. 4. Mechanical strain gauge.

\section{Theoretical and experimental analysis for results}

According to the measurements made at each wall from all walls of the researched samples, the mean shrinkage strain values were produced for both types of samples. Strain progress (Fig. 5a) and water mass loss (Fig. 5b), for the S1 and S2 samples in the research period, as well as environmental humidity changes in the chamber (Fig. 5c), are presented in figure 5.

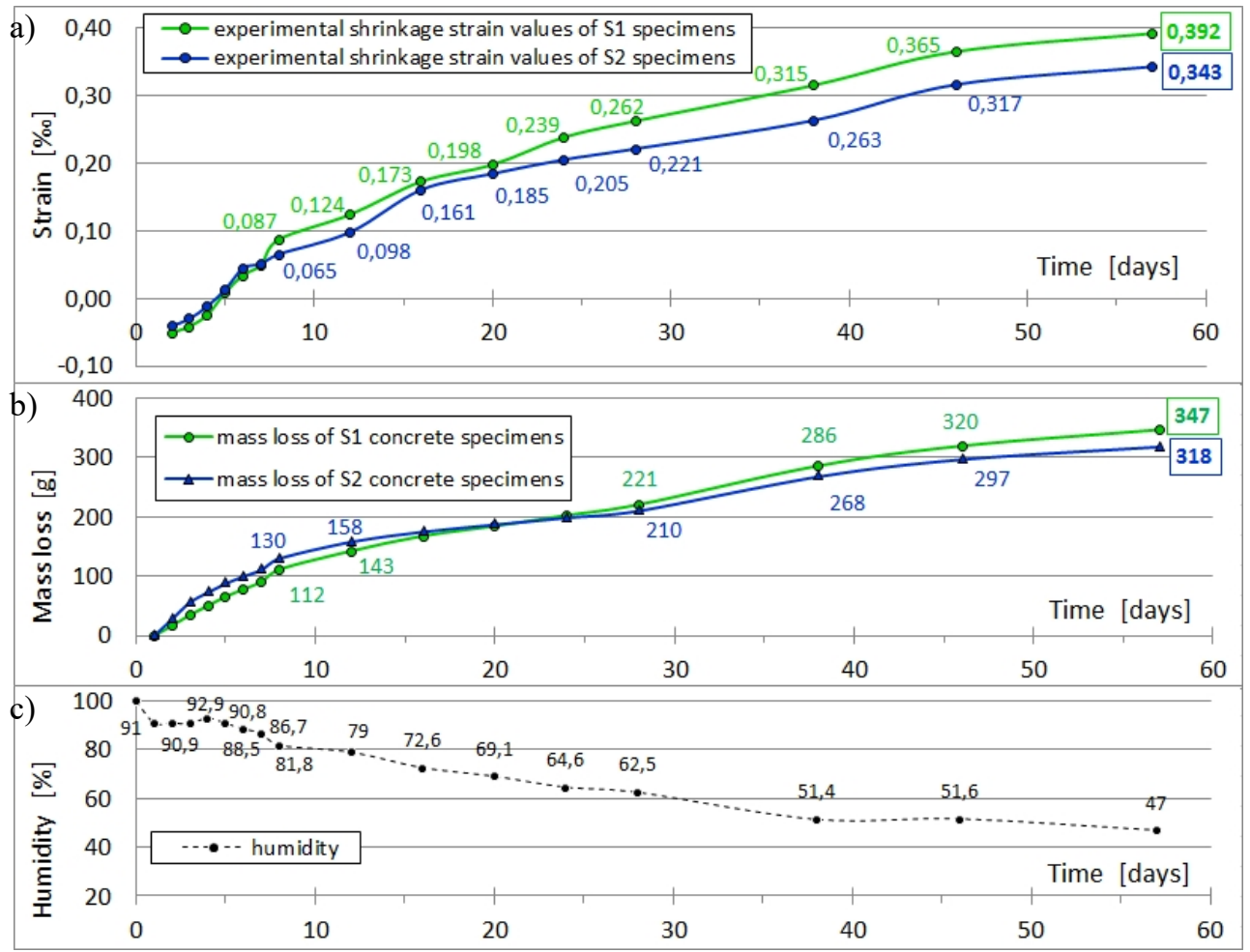

Fig. 5. a) Graph for mean strains in the $S 1$ and $S 2$ samples, b) Graph for water mass loss in the $S 1$ and S2 samples, c) Humidity conditions during the experiment. 
When analysing the graphs shown in figure 5, an almost identical course of strains in the S1 and S2 concrete is observed in the first research week, namely at time when the environmental humidity exceeded $80 \%$. Strain growth in this period amounted to $0,015 \%$ /day and water mass loss $15 \mathrm{~g} /$ day, for both concretes. After the first research week, when the environmental humidity started to fall below $80 \%$, differences in the shrinkage values for the S1 and S2 samples were observed, which most probably resulted from the application of two various cement types in the samples. The shrinkage strain values in the Portland cement (S1) samples were higher from those observed for the blast furnace cement (S2) concrete. Difference in strain values ranged from $0.012 \%$ to $0.041 \%$. Increase in the water mass loss in the S1 samples was also higher in this period and amounted to $5.5 \mathrm{~g} / \mathrm{day}$, in average, when compared to the S2 elements ( $2.5 \mathrm{~g} /$ day). From the 36 th -57 th research day, difference between strain values in the S1 and S2 elements stayed at the level of $\approx 0.050 \%$, increase in the water mass loss in the $\mathrm{S} 1$ elements decreased to $2.9 \mathrm{~g} /$ day, but it amounted to $2.4 \mathrm{~g}$ /day for the $\mathrm{S} 2$ samples.

The following part of research analysis is oriented on the verification of evaluation model for the shrinkage strain progress, provided in the [10] standard (respective for evaluation of strains in the concrete classes $\mathrm{C} 30 / 37$ and $\mathrm{C} 40 / 50$ ), based on actual results obtained for the S1 sample (with Portland cement) and the S2 (with blast furnace cement). In figure 6, for both sample types total shrinkage strain were evaluated and compared with the experimentally measured strains, in relation to the environmental humidity.



Fig. 6. Graph for mean shrinkage strains for the $\mathrm{S} 1$ and $\mathrm{S} 2$ samples, in relation to the guidelines from the standard.

It is demonstrated in the analysis results, that in the first research week, when the environmental humidity exceeded $\mathrm{Rh}=80 \%$, a large difference between strains provided experimentally and strains evaluated according to the standard [10] were observed, both in the S1 samples (with Portland cement) and the S2 samples (with blast furnace cement). In the S1 samples the largest differences in strain values occurred in the environmental humidity exceeding $\mathrm{RH}=82 \%$ and amounted to $0.069 \%$, whereas for the $\mathrm{S} 2$ samples in the $\mathrm{RH}=88 \%$ humidity and they amounted to $0.053 \%$. The above analysis results encourage the greater number of research focused on compatibility of the experimental and model results in the environmental humidity exceeding $80 \%$, with possible application of correction to the shrinkage evaluation method according to the [10], or for limiting the 
scope of application for formulas, when environmental humidity exceeds $\mathrm{RH}=80 \%$, similarly to the case of [11] standard, or for modification of current formulas.

\section{Conclusions}

1. It is confirmed in the conducted experimental research, that the environmental humidity and type of the cement used have significant influence on the course and size of shrinkage strains.

2. Replacing the CEM III blast furnace cement with the CEM I Portland cement advantageously influences the limitation of shrinkage, in the case of environmental humidity exceeding $80 \%$.

3. Type of the cement used (Portland CEM I or blast furnace CEM III) does not have an influence on the changes in shrinkage strain values in the first measurement week, when the environmental humidity exceeds $\mathrm{RH}=80 \%$.

4. Large differences exist between the shrinkage strain values obtained from the experimental research and those evaluated according to the [10] standard, when the environmental humidity exceeds $\mathrm{RH}=80 \%$. Nevertheless, this standard allows for application of formulas in case of the humidity between $40 \%$ and $100 \%$.

5. The authors suggest a greater amount of shrinkage research in humidity conditions exceeding $80 \%$, in order to verify the applicability range for normative regulations.

\section{References}

1. K. Flaga, (Concrete shrinkage and its influence on capacity, serviceability and durability of reinforced and prestressed concrete structures, PK Publisher, Cracow, 2002)

2. K. Flaga, (Shrinkrage stress and subsurface reinforcement in concrete structures, PK Publisher, Cracow, 2011)

3. A. Lapko, (Design of reinforced concrete structures in acordance of Eurokod 2 and $P N-B-03264: 1999$ standard, Arkady, Warsaw, 2001)

4. K. Flaga, Bull. Pol. Ac. Tech, 63, 1, 15-22 (2015)

5. Z. Giergiczny, Reinforced concrete, 1, 305-346, PZIiTB Gliwice (2018)

6. J. Gołaszewski, Motorways, 5, 14-18 (2016)

7. A. Garbacik, W. Drożdż, Z. Giergiczny, Underground Infrastr. of Urban Areas, 3, 13-20 (2015)

8. P. Kossakowski, W. Raczkiewicz, AMS, 14/2, 5-13 (2014)

9. W. Raczkiewicz, M. Bacharz, K. Bacharz, AMS, 15/2, 22-29 (2015)

10. PN-EN 1992-1-1:2008 Eurocode 2: Design of concrete structures - Part 1-1: General rules and rules for buildings

11. PN-EN 1992-2:2010 Eurocode 2: Design of concrete structures - Part 2: Concrete bridges - Design and detailing rules

12. PN-EN 206-1:2003 Concrete - Part 1: Specification, performance, production and conformity

13. ITB Instruction No 194/98: Study of mechanical properties of concrete on samples taken in the forms, (in Polish), ITB, Warsaw (1998) 